\title{
Realidad actual. Lo que podemos aprovechar
}

\author{
Dr. Fernando A. Lopreite \\ Presidente de ACARO
}

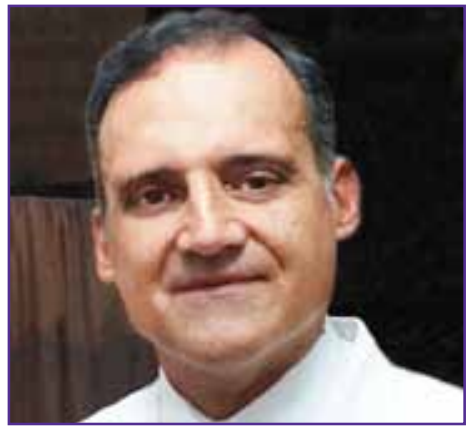

\begin{abstract}
A partir de la situación sanitaria que nos afecta, nuestra vida se ha modificado y no está exenta de ello nuestra profesión.
\end{abstract}

En lo concerniente a la cuestión educativa, la virtualidad ha tomado un rol fundamental y, como muchos dicen, ha venido para quedarse. Sin duda que la presencialidad en lo educativo es esencial, pero la virtualidad nos permite abarcar y llegar a lugares que, muchas veces, son difíciles de acceder por las distancias. Además, permite una educación más abarcadora y federal, y también nos da la posibilidad de llegar a colegas de otros países.

En lo referente al acto médico y específicamente a la patología degenerativa de la cadera y la rodilla, nos hemos encontrado con la situación de que sea considerada patología "no urgente". Esto nos ha enfrentado a situaciones en las cuales los pacientes que se encuentran limitados severamente por la discapacidad y el dolor no reciban la atención médica quirúrgica adecuada, y se deban posponer las cirugías correspondientes. Nuestra Asociación se ha expresado al respecto con una nota referenciada en un trabajo científico titulado "Worse than death" and waiting for a joint arthroplasty (Bone Joint J 2019) y que pueden encontrar en nuestra página web. En este artículo, se hace una evaluación de los pacientes dentro del sistema sanitario británico, que están en lista de espera para una artroplastia y en el deterioro físico y mental que ello genera. Esto se puede replicar en la situación actual y es de fundamental importancia entender que los pacientes que sufren esta afección merecen, dentro de las posibilidades que el sistema sanitario lo permita, ser considerados para el tratamiento quirúrgico correspondiente dentro de un grupo prioritario. Es nuestra responsabilidad informarnos y transmitir a los colegas de otras especialidades, como terapistas, infectólogos y clínicos en general, así también como a los auditores de Obras Sociales y Prepagas, sobre esta realidad en este grupo de pacientes.

Por otra parte, a nosotros, como profesionales de la salud, nos corresponde sacar provecho de esta difícil situación, mejorando al máximo la condición en que nuestro paciente ingresa en el quirófano y optimizar el posoperatorio para que el paciente pueda ser dado de alta lo más rápido posible, en condiciones adecuadas, no solo para disminuir el riesgo de contagio de la COVID-19, sino para ocupar por el menor tiempo posible una cama.

En definitiva, como se dice habitualmente, cada crisis es una oportunidad. Tratemos de aprovechar esta y es un gran deseo que, en un futuro cercano, podamos volver a encontrarnos presencialmente para continuar compartiendo nuestros conocimientos y experiencia.

Les mando un gran abrazo.

Dr. FERNANDO A. LOPREITE • fernandolopreite@ hotmail.com (ID) https://orcid.org/0000-0002-2065-8649

Cómo citar este artículo: Lopreite FA. Realidad actual. Lo que podemos aprovechar. Rev Asoc Argent Ortop Traumatol 2021;86(4):443. https://doi.org/10.15417/issn. 1852-7434.2021.86.4.1398 